\title{
Energy-Saving Ventilation System for Sheep Premises
}

\author{
M.Zh. Issakhanov, N.B. Alibek, T.S. Dyusenbayev, A.S. Taldybayeva \\ Kazakh National Agrarian University, Almaty, Kazakhstan,
}

\begin{abstract}
The system works by using the soil warmth, i.e. a renewable source of energy and contributes to environmental protection. The results of theoretical and experimental studies of an energy-saving ventilation system using soil heat are presented. The use of an energy-saving ventilation system reduces energy and labor costs for creating a microclimate in sheep premises. The device of an energy-saving ventilation system is protected by the patent of RK KZ 26930 dated 15.07.2016
\end{abstract}

Keywords: Energy-saving ventilation system, underground heat exchanger, air duct, soil heat, temperature sensors, relative humidity and temperature sensors, Masterscada system.

\section{INTRODUCTION}

Rational use of fuel and energy resources is one of the world's global problems today. One of the promising ways to solve this problem is the use of new energy-saving technologies using non-traditional renewable energy sources.

The range of applications of renewable energy sources on farms is quite wide: this includes heating or cooling buildings, drying agricultural products, desalination or heating water, and even autonomous energy supply [1].

The advantages of such energy sources are environmental cleanliness and low labor and money costs for the operation of installations for their use. The solution to the problem of energy saving in agricultural ventilation systems is the effective use of low-potential soil heat. The soil of the surface layers of the Earth is actually a thermal accumulator of unlimited capacity, the thermal regime of which is formed under the influence of solar radiation. Low-potential heat of the Earth can be used in agricultural premises for heating, hot water supply, air conditioning (cooling).

There are a number of examples of the use of soil heat for heating and cooling livestock premises through underground air ducts and heat exchangers. They have saved from 50 to $75 \%$ of the cost of heating and cooling the premises [1-12]. The study of these examples allowed to develop an energysaving ventilation system for sheep premises .

Figure 1 shows the functional scheme of the ventilation system; Figure 2 - section on A-A of Figure 1; Figure 3 block scheme of the control of the electric motor and control valves of the supply air ducts and air funnel, spray and closers.

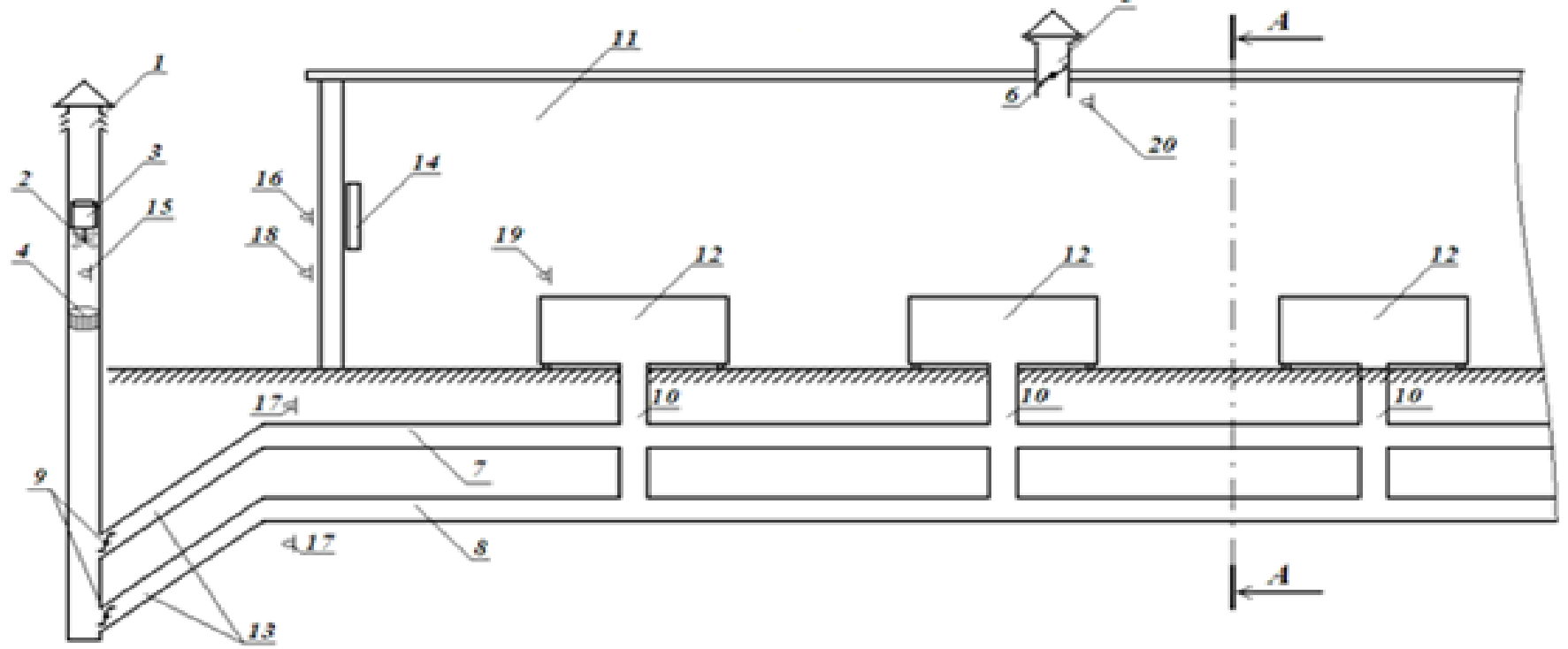

Figure 1: Functional scheme of the ventilation system 


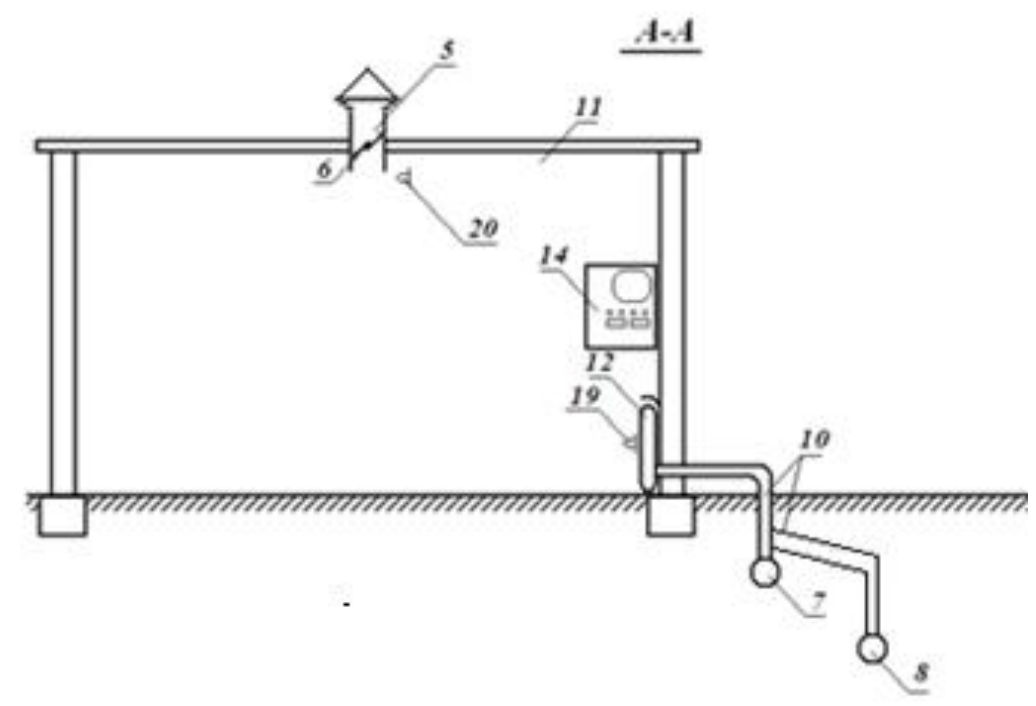

Figure 2: Section on A-A of Figure 1

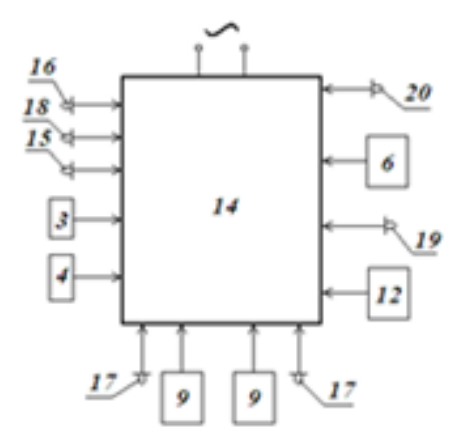

Figure 3: Block scheme of control of the electric motor and control valves of the supply air ducts and air funnel, sprayer and closers

Ventilation device (Fig. 1) contains an air inlet duct 1 equipped with a fan 2 and an electric motor 3 and a water sprayer 4, an air funnel 5 with a control valve 6 and supply air ducts 7,8 with control valves 9 air outlets 10 to a ventilated room 11 with temperature closers 12 , connected by means of a pneumatic lock 13 with an air inlet duct 1 and placed in the soil below the freezing mark of the latter and a program climate controller 14 with temperature sensors 16, 17, 19,20 and speed 15, humidity 18 , connected to the electric motor 3 of the fan 2 by the control valve 6,9 of the air funnel and supply air ducts 7,8 and the spray 4 and closers 12 of the temperature.

The device contains two supply air ducts 7,8 to ensure the continuity of the supply of heated air to the room 11 while charging one of them.

Assembly and manufacturing of the ventilation device is carried out from prefabricated modular elements selected in accordance with the volume of required ventilation air and the type of agricultural premises.

In the cold period of the year, heavy fresh air flows into the air inlet duct 1 and enters the open air duct 7 through the air lock 13, contacts the surface of its walls, is heated by the soil heat and moves up, exits through the outlets $10 \mathrm{c}$ room 11, flowing around the temperature closer 12 .

The air lock 13, the threshold of which is located below the bottom of the air ducts 7, 8 does not allow the exit of heated light air from the air duct to the air inlet duct 1 . This ensures strictly one-way gravity movement of fresh air.

The exhaust air is withdrawn from the ventilated room through the air funnel 5 with a control valve 6 , which is controlled by the microclimate program controller 14 .

The program controller 14 controls the operation of the electric motor 3 of the fan 2, which supports the set speed of the gravity flow and the control valves 9, supply air ducts 7, 8, providing a set threshold for the temperature of the gravity flow, as well as the temperature closer.

As the temperature of the walls of the air duct 7 or the soil mass decreases, the intensity of heat removal decreases and at a certain temperature value, the set threshold exceeds the normalized value. At this moment, at the signal of the soil temperature sensor 17 , the microclimate controller 14 closes the supply air duct control valve 7 and opens the air duct valve 8 . The soil mass around the air duct 7 recovers its natural temperature after a while, i.e. it is recharged, and the soil mass around the air duct 8 is cooled, i.e. it is discharged. When the soil temperature reaches the normalized value by means of the sensor 17 , the microclimate controller 14 closes the valve 9 of the supply air duct 8 and opens the valve 9 of the air duct 7. Thus, the supply air ducts alternately operate in charging and discharging mode, and provide a normalized stable supply air temperature, i.e., stabilization of the supply air temperature.

The heated supply air supplied to the room flows around the temperature closer 12 , its temperature rises to the normalized value. Enabling and disabling closers is carried out by the microclimate controller 14 via the temperature sensor 19 . 
Closers 12 provide radiant and convective heat exchange in the process of creating a local microclimate.

The valve 6 of the air funnel 5 regulates the outlet of exhaust air, its operation is controlled by the microclimate regulator 14 by means of a temperature sensor 20 .

As the external temperature increases, the speed of the gravity flow decreases and at a certain temperature value, the flow rate will be insufficient to provide a normalized air exchange. At this moment, at the signal of the outdoor temperature sensor 16 and the flow rate sensor 15 , the microclimate controller 14 connects the electric motor 3 of the fan 2 .

In the warm period of the year, the heated fresh air is pumped by a fan 2 through the air inlet duct 1 into the air duct 7 , from where the air enters the ventilated room through the outlets 10. When passing through the air duct 7 , the heated fresh air is cooled by transferring heat to the soil through its walls. Air ducts 7, 8 will also work in discharge and charging mode as during the cold period of the year.

Depending on the required humidity parameters of the ventilated fresh air, it is moistened with water through a spray 4.

The sprayer 4 is controlled via the microclimate controller 14 by means of the outdoor humidity sensor 18 and provides the required humidity of the supplied air.

According to this scheme, an experimental energy-saving ventilation system for a sheepfold was designed and built, and production tests were conducted during the lambing period.

\section{METHODS OF RESEARCH}

When designing an energy-saving ventilation system, the differential equation of the soil temperature field around the air duct of the ventilation system is considered [15-19].

$$
\frac{\partial t}{\partial \tau}=a\left(\frac{\partial^{2} t}{\partial R^{2}}+\frac{1}{R} \frac{\partial t}{\partial R}\right)
$$

where $a$ is the thermal conductivity of the soil.

Boundary conditions of equation (1):

$$
\begin{aligned}
& t=t_{s} a t 1 . \tau=0 ; 2 . R \rightarrow \infty, \tau \geq 0 \\
& \text { 3. }-\lambda \frac{\partial t}{\partial R}=\alpha\left[t\left(R_{o}, \tau\right)-t_{s}(\tau)\right]=0
\end{aligned}
$$

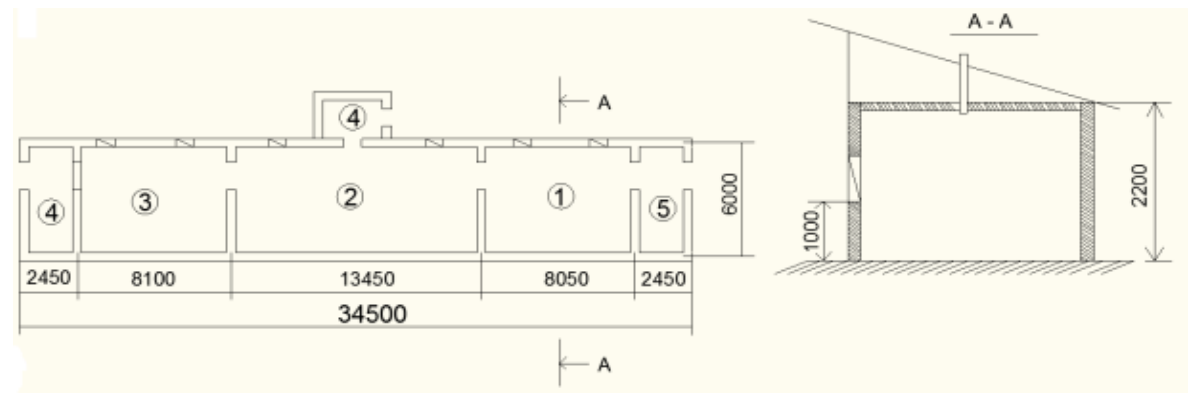

1 - maternity barn; 2 - room for keeping sheep; 3 - room for keeping lambs from 2 months; 4 - tambours; 5 - electric board.

Figure 4: Plan of the sheepfold for lambing where $\lambda$ is the thermal conductivity of the soil;

$\alpha$ - coefficient of heat transfer of the channel walls.

Average integral air temperature along the length of the channel with the total heat exchange area $F$ :

$$
t_{a v}(\tau)=\frac{1}{F} \int_{0}^{F} t(x, \tau) d F
$$

where $t(x, \tau)$ is the local temperature, determined from the heat balance equation of the air duct area $d F$ :

$$
c G d t=\alpha\left[t\left(R_{o}, \tau\right)-t(x, \tau)\right] d F
$$

The solution of equation (2) has the form:

$$
\varphi_{x}=\frac{t(x, \tau)-t\left(R_{o}, \tau\right)}{t_{0}-t\left(R_{o}, \tau\right)}=\exp \left(\frac{-\alpha F_{x}}{c G}\right)
$$

where $t\left(R_{o}, \tau\right)$ - the average length of the channel wall temperature at the time under consideration; $F_{\tilde{o}}$ - the heat exchange area of the channel to the cross-section $x$.

The solution of the differential equation allowed to calculate the parameters of energy-saving ventilation system.

A special information and measurement system was developed to record the thermal parameters of the ventilation system, i.e. the temperature of the outdoor, indoor air, soil and relative humidity of the outdoor and indoor air.

\section{RESULTS AND DISCUSSION}

An experimental energy-saving ventilation system was built in a sheepfold for lambing in the Almaty region. The plan and photograph of the sheepfold are shown in Figures 4 and 5. 


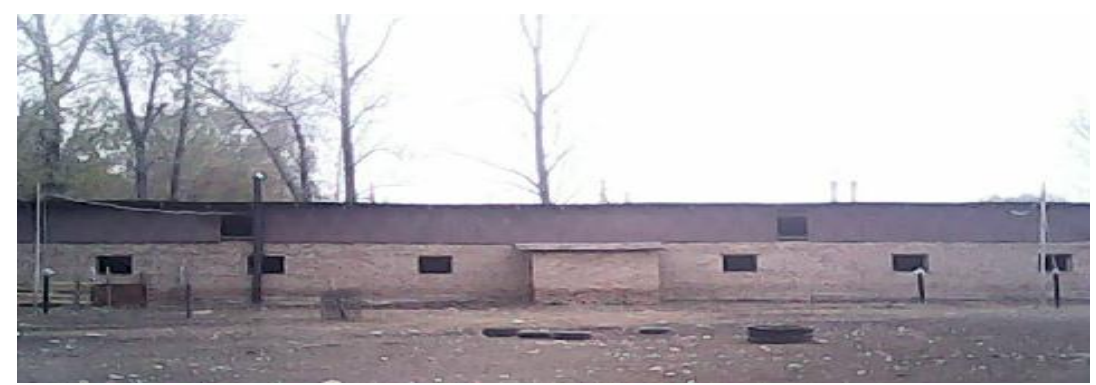

Figure 5: Sheepfold for lambing

The scheme of an experimental energy-saving ventilation system for a sheepfold is shown in Figure 6.

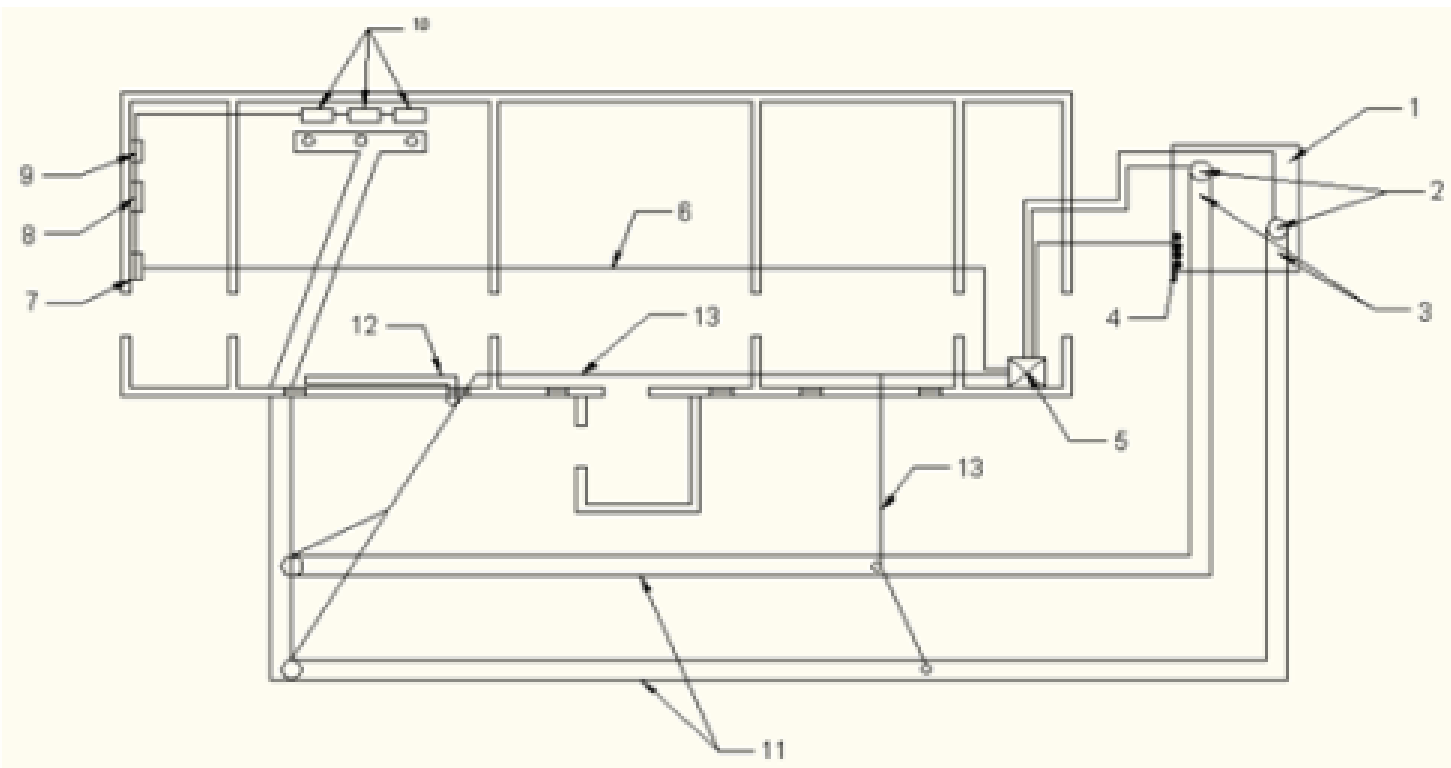

1 - room of the air inlet duct; 2 - supply vertical air ducts; 3 - supply horizontal air ducts; 4 - ground temperature sensors; 5 - control cabinet; 6 - power wiring; 7 - power board; 8 - electric meters; 9 - reducing transformer 220/22 V; 10 - closers - electric heating panels; 11 - underground heat exchangers-horizontal air ducts; 12 - air funnel with air duct; 13 - sensor wiring.

Figure 6: Flow chart of an experimental energy-saving ventilation system for a sheepfold

Underground heat exchangers - air ducts were made of corrugated plastic pipes produced by "EPA Almaty" LLP. Pipes are made of high-density polyethylene with a nominal internal diameter from $110 \mathrm{~mm}$ to $630 \mathrm{~mm}$. GOST 185992001.

Wall profile of the "corrugation" type. The pipes are manufactured with a spigot and socket connection. They are connected via o-ring. They have a hollow structure in the form of hollow channels of rectangular cross-section perpendicular to the axis of the pipe section, the inner layer is straight and smooth.

The specially designed outer surface of the pipes has a high ring stiffness and makes them more resistant to compressive loads (transport, soil water, permafrost and soil compaction), and the elastic structure of the pipes protects them from destruction when exposed to overloads. As a material, highdensity polyethylene has: high tensile strength, high thermal stability and is not subject to corrosion.
Production tests of the energy-saving ventilation system were carried out in two stages: winter and summer [21-24].

When testing an energy-saving ventilation system in winter, it was found that the air temperature in the sheepfold premises ranged from $+5.4{ }^{\circ} \mathrm{C}$ to $+6.0{ }^{\circ} \mathrm{C}$, on average $+5.6{ }^{\circ} \mathrm{C}$, with the number of measurements $n=72$.

The relative humidity of the sheepfold premises averaged

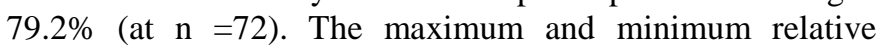
humidity values were $93.4 \%$ and $64.1 \%$, respectively. At the lowest outdoor temperature $-18^{\circ} \mathrm{C}(04.02 .2014)$, the supply air temperature reached $+6^{\circ} \mathrm{C}$. The flow rate of the supplied air varied between $70-140 \mathrm{~m}^{3} / \mathrm{h}$ depending on the outdoor air temperature. The maximum heat output of the unit was 2.2 $\mathrm{kW}$.

When testing an energy-saving ventilation system in summer, it was found that the air temperature in the sheepfold premises ranged from $+16.6^{\circ} \mathrm{C}$ to $+27.29^{\circ} \mathrm{C}$, on average $+22.3^{\circ} \mathrm{C}$, with the number of measurements $n=820$. 
The relative humidity of the sheepfold premises averaged $30.5 \%$ (at $\mathrm{n}=820$ ). The maximum and minimum relative humidity values were $58.88 \%$ and $10.37 \%$, respectively. At the highest outdoor temperature of $+33.4^{\circ} \mathrm{C}$, the supply air temperature reached $+19.6^{\circ} \mathrm{C}$, and the humidity increased from $12 \%$ to $23 \%$. The flow rate of the supplied air was 140 $\mathrm{m}^{3}$ /hour. The cooling capacity of the unit was $2.6 \mathrm{~kW}$.

\section{CONCLUSION}

A mathematical model of heat exchange processes in an energy-saving ventilation system has been developed. The ratio of the optimal radius and length of the air duct, the air flow rate of the soil temperature and the volume of heat in the ventilation system are determined.

The technological, functional and concept schemes of an energy-saving ventilation system has been compiled. The parameters of a ventilation system for a sheepfold using soil heat were determined.

Production tests of an experimental modular energy-saving ventilation system were carried out in two stages: winter and summer.

Registration of thermal parameters of the ventilation system was performed remotely using the MasterScada system.

Assessment of the technical and economic efficiency of the work performed shows that when implementing an energysaving ventilation system, energy consumption is reduced by up to $40-50 \%$, depending on the type of agricultural premises.

During the testing periods, the energy-saving ventilation system provided the energy-saving mode and the required zootechnical parameters of the microclimate in the maternity barn of the sheepfold.

The energy-saving ventilation system was adopted for economic use and recommended for implementation in sheep farms

\section{REFERENCES}

[1] Stepanova V.E.(1989). Renewable energy sources in agricultural enterprises. - Moscow: Agropromizdat, p. 112 A. S. 250589 (USSR) Vent unit (T.Ya. Andryukhin, Pub. in B. N. 1969. No. 26).

[2] Vasileva B.V., Koslacheva E.M., Folitarin A.M. et al.(1986). Use of soil heat in ventilation and heating systems. // "Heat pipe and heat exchangers with capillary-porous structure". - Minsk, pp. 117-123.

[3] Shildkret V.M., Vasileva I.M., Krasikov K.I.(1990). Application of non-traditional energy sources in heat supply systems. // Water supply and sanitary technique. - No. 10 - pp. 8-11.

[4] Vasiliev L.L.(1990). Using the Earth's energy with the help of heat pipes. // Engineering and physical journal. - No. 3. - pp. 488-492.

[5] Draganov B.Kh.(1988). Use of renewable and secondary energy resources in agriculture. - Kiev, Higher school. Head publishing house, p. 156, Il.
[6] Khromets D.Yu., Vasiliev G.P.(1985). Method of energy assessment of the use of soil heat for heat and cooling supply of buildings. //"Research of thermal insulation of buildings" - Moscow: pp. 71-74.

[7] Vasileva B.V., Kamecheva E.M., Folitarin A.M. et al. (1986); Use of soil heat in ventilation and heating systems. // "Heat pipes and heat exchangers with capillary-porous structures" - Minsk, pp. 117 to 123.

[8] Severnev M.M. (1992).Energy-saving technologies in agricultural production. - Moscow: Kolos. p.190 Il.

[9] Kokorin O.Ya., Abbasov A.M., Aliev N.D. (1990).The use of thermal energy of soil for the microclimate on livestock farms // Refrigeration equipment. No. 2, - pp. 13-16.

[10] Gumerov , M.Sh. (1992).Use of underground air ducts for cooling ventilation air. // Materials of the anniversary scientific conference. Kazan Agricultural Institute. 42 - Kazan, pp. 192-194.

[11] Twysell J., Ware A.(1990). Renewable energy sources. / Trans. from the English. Moscow: Energoatomizdat, . p.332.

[12] Egiazarov, A.T.(1990). Energy problems of agroindustrial complex // Water supply and sanitary equipment. - No. 5. - pp. 2-4.

[13] Renewable energy sources and their choice. Renewable energy: the power to choose. Dendnev Daniel, Flavin, Christopher. // “Jnt.J. Amlient Energy". - 1984. - No. 3. - p.168.

[14] Patent of RK. No. 26930 dated 15.07.2016 "Ventilation device", Issakhanov M.Zh., Alibek N.B., Doldayev O.Z., Dyusenbayev T.S., etc.

[15] Lykov A.V. (1967).Theory of thermal conductivity. Moscow: Higher school, 1967. - p.539.

[16] Vardiashvili, A.B., Muradov, M.U., Kim, V.D. (1987).Mathematical model of a pebble heat accumulator and method of its heat engineering calculation. // Thermotechnics. No. 2. - pp. 38-43.

[17] Prokhach E.E., Klepanda A.S., Bogdanovich L.S.(1990). Calculation of non-stationary heat transfer in geo-ventilation systems // Problems of energy saving. No. 5. - pp. 40-43.

[18] Prikhodko I.M., Klepanda A.S., Kuznetsov A.P.(1991). Calculation of non-stationary heat transfer processes in soil batteries of solar type // Solar engineering. - 1991. No. 1. - pp. 70-74.

[19] Kirsanov M.N. Maple и Maplet. (2012).The solution of mechanics tasks: a tutorial. - SPb.,: "Lan" Publishing House, p. 512.: il.

[20] Installation for the microclimate on livestock farms / D.N. Murusidze, A.M. Zaitsev, N.A. Stepanova et al. ed. 2nd, proc. and add. - M.: Kolos, 1979. - p. 327; il.

[21] Karelin A.I., Maravin B.L.(1987). Zoo-hygienic bases of design, construction and operation of livestock facilities. Moscow: Rosselkhozizdat. p.271: il.

[22] Issakhanov M.Zh., Alibek N.B., Dyusenbayev T.S.(2014). Energy-saving ventilation system for sheep premises. Proceedings of the 9th international scientific and technical conference energy supply and energy saving in agriculture. Part 3. Moscow, pp. 100-103.

[23] Issakhanov M., Sakipova Sh., Alibek N., Dyusenbaev 
International Journal of Engineering Research and Technology. ISSN 0974-3154, Volume 13, Number 11 (2020), pp. 3685-3690

(C) International Research Publication House. https://dx.doi.org/10.37624/IJERT/13.11.2020.3685-3690

T. (2017).On the simulation of energy-saving ventilating system. SCIENCE AND WORLD. International scientific journal. Founder and publisher: Publishing House «Scientific survey» № 10 (50. Vol. I. P 59-62.

[24] Issakhanov, M., Alibek, N., Dyusenbayev, T. (2014). Energy saving ventilation systems for sheep premises. International journal International scientific, scientific applied and informational journal mechanization in agriculture. 7/2014, Sofia, Bulgaria «Energy saving ventilation systems for sheep premises». 